\title{
Congenital Complete Absence of the Left Pericardium
}

\author{
Anca Filip Flintoaca, R.Al. Capsa, Ioana Gabriela Lupescu
}

Department of Radiology, Medical Imaging and Interventional Radiology

Corresponding author:

Fundeni Clinical Institute, Bucharest, Romania

Ioana Gabriela Lupescu, MD, Phd

Department of Radiology

Medical Imaging and Interventional

Radiology, Fundeni Clinical Institute

Bucharest, 258 Fundeni Street

Romania

E-mail: ilupescu@gmail.com

\section{ABSTRACT}

Congenital absence of the pericardium is a rare condition, which can be isolated, but most frequently associated with other cardiac or extracardiac congenital anomalies. Generally, most the patients with pericardial absence are asymptomatic. In some cases, partial pericardial defects can be life threatening, because of heart and lung herniation and ventricular entrapment. The pericardium has a supporting and protecting role for the heart and the proximal great vessels (ascending aorta and pulmonary arterial trunk), so absence of the pericardial layers allows important thoracic displacement of the heart. Diagnosis is established by the relevant radio-imaging findings suggestive of complete absence of the pericardium, with characteristic cardiac silhouette abnormalities. We present a case with complete absence of the left pericardium in an asymptomatic young male patient. A review of literature focusing on congenital pericardial defects and the radiological findings of this condition, focused on cardiacMR imaging, is also presented.

Key words: congenital pericardial absence, CMR imaging, pericardium

\section{INTRODUCTION}

Congenital pericardial absence is a rare condition and usually there is an association with other congenital heart diseases (1-6) or thoracic anomalies (1-3). The most common congenital pericardial defect is on the left side (3), often asymptomatic and usually identified incidentally (6). CMR imaging provides best delineation of the entire pericardium (3).

\section{CASE REPORT}

We report a case of a 12 years old male patient with no significant symptoms. In a routine chest $x$ ray was noted important leftward displacement of the heart and rectification of the left heart border. An echocardiogram raised the suspicion of congenital absence of the pericardium. Cardiac magnetic resonance 


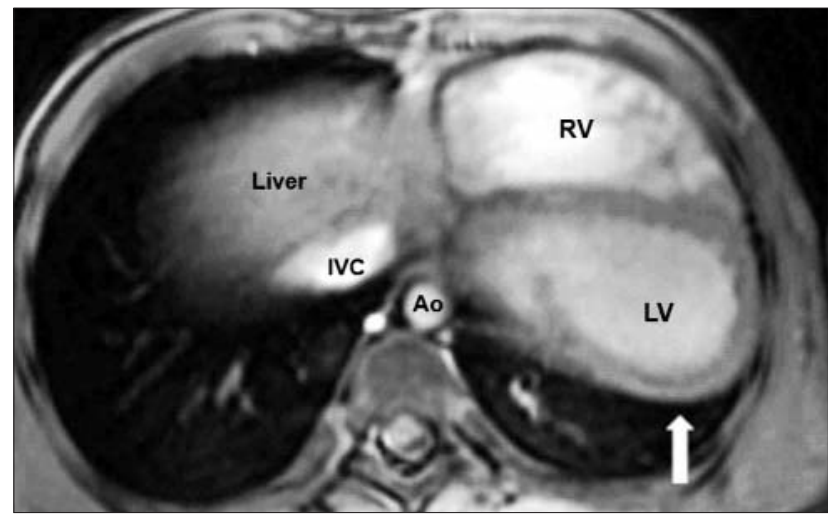

Figure 1 - CRM-CINE image in axial view illustrating posterior displacement of the cardiac apex (arrow); the pericardium is totally lacking over the whole surface of the left ventricle
(CMR) imaging was performed to investigate for cardiac abnormalities. CMR imaging showed posterior displacement of the cardiac apex (fig. 1) and important leftward displacement of the heart (fig. 2). Pulmonary arterial trunk was protruding towards the left lung (fig. 3). In the aorto-pulmonary window was noted lung parenchyma interposition between ascending aorta and proximal portion of the pulmonary arterial trunk (fig. 3). The left ventricle was in direct contact with the left lung (fig. 1). Both ventricles were normal for morphology, and there are no signs of left ventricular entrapment through the pericardial defect (fig. 4). No ventricular septal defect was noted (fig. 4).

\section{DISCUSSION}

Congenital pericardial absence is a rare condition, with a frequency of $0,002-0,004 \%$ (6). Usually there is an association with other congenital anomalies (approximately $30-50 \%$ of the cases) $(2,6)$, most frequent patent ductus arteriosus, bronchogenic cyst, atrial septal defects, left diaphragmatic hernia etc $(2,3,6)$.

Failure of pleuropericardial membrane closure during development (1) or premature atrophy of the left common cardinal vein, with consequent reduced blood supply to the left pleuropericardial membrane $(1,3)$, are generally considered main causes of pericardial agenesis.

Pericardial defects range from partial (subgroup foramen-type defects) $(7)$ to complete (bilateral) $(7,8)$ and are classified for their positions as right or left sided (3). Complete absence of the left pericardium is the most frequent defect $(5,9)$, represents approximately $70 \%$ of all pericardial defects $(2,3,6)$.

The pericardium has a supporting and protective
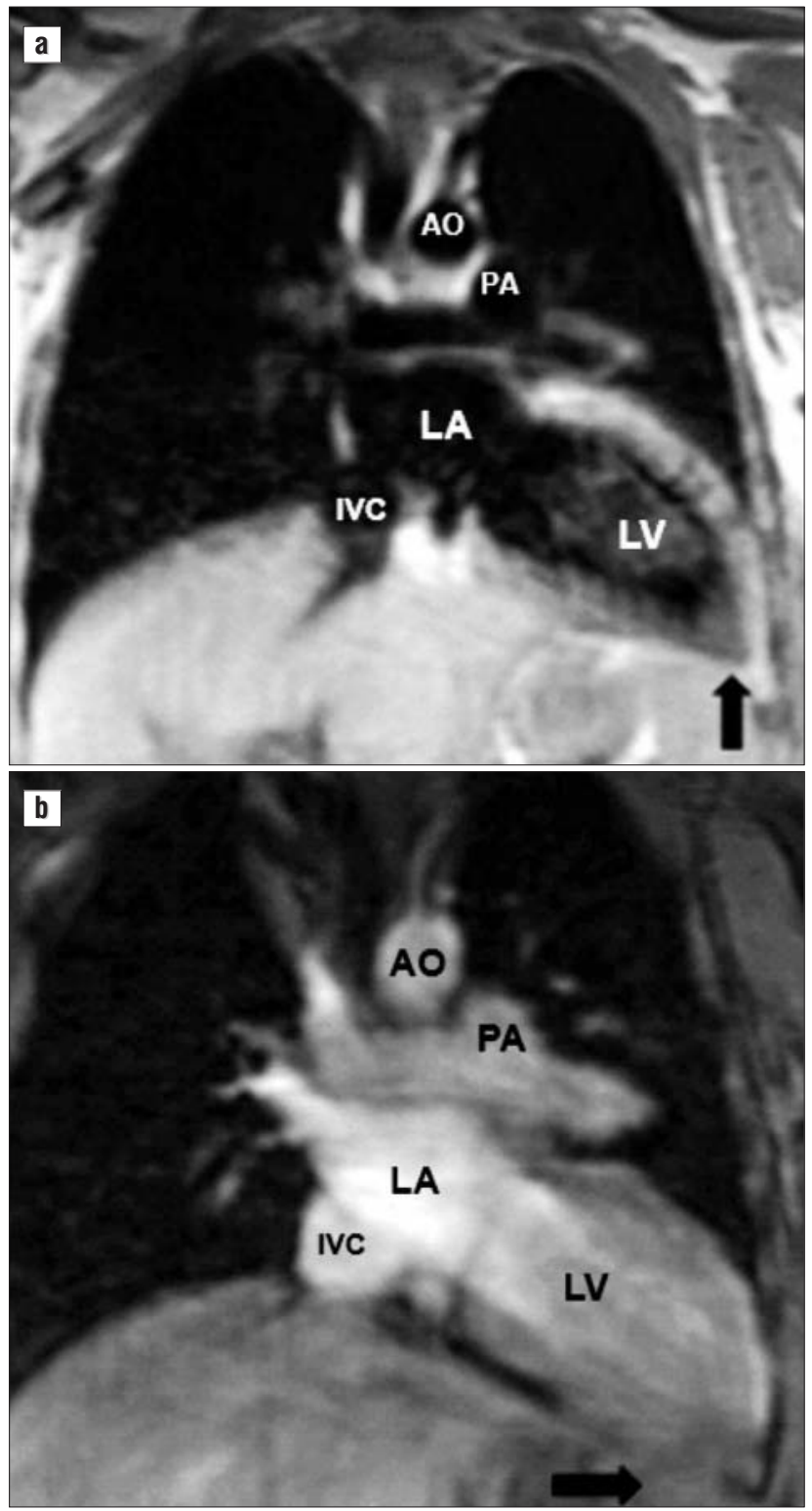

Figure 2 - T1 SE wi (black blood-a) and CINE (b)-CMR imaging in coronal view showing leftward displacement of the heart and the cardiac apex oriented toward the lateral costodiaphragmatic sulcus (black arrow)

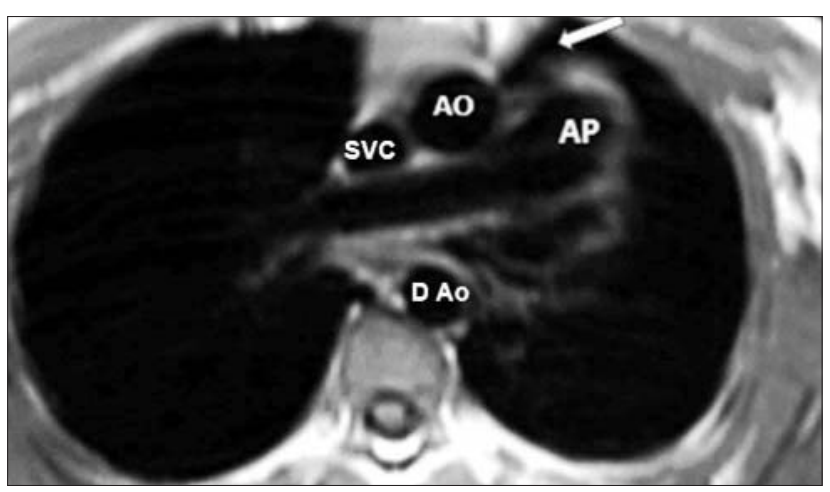

Figure 3 - T1 SE wi in axial view (black blood) showing pulmonary arterial trunk (AP) protruding toward the left lung and lung parenchyma interposition between ascending aorta (A Ao) and pulmonary arterial trunk (AP) 

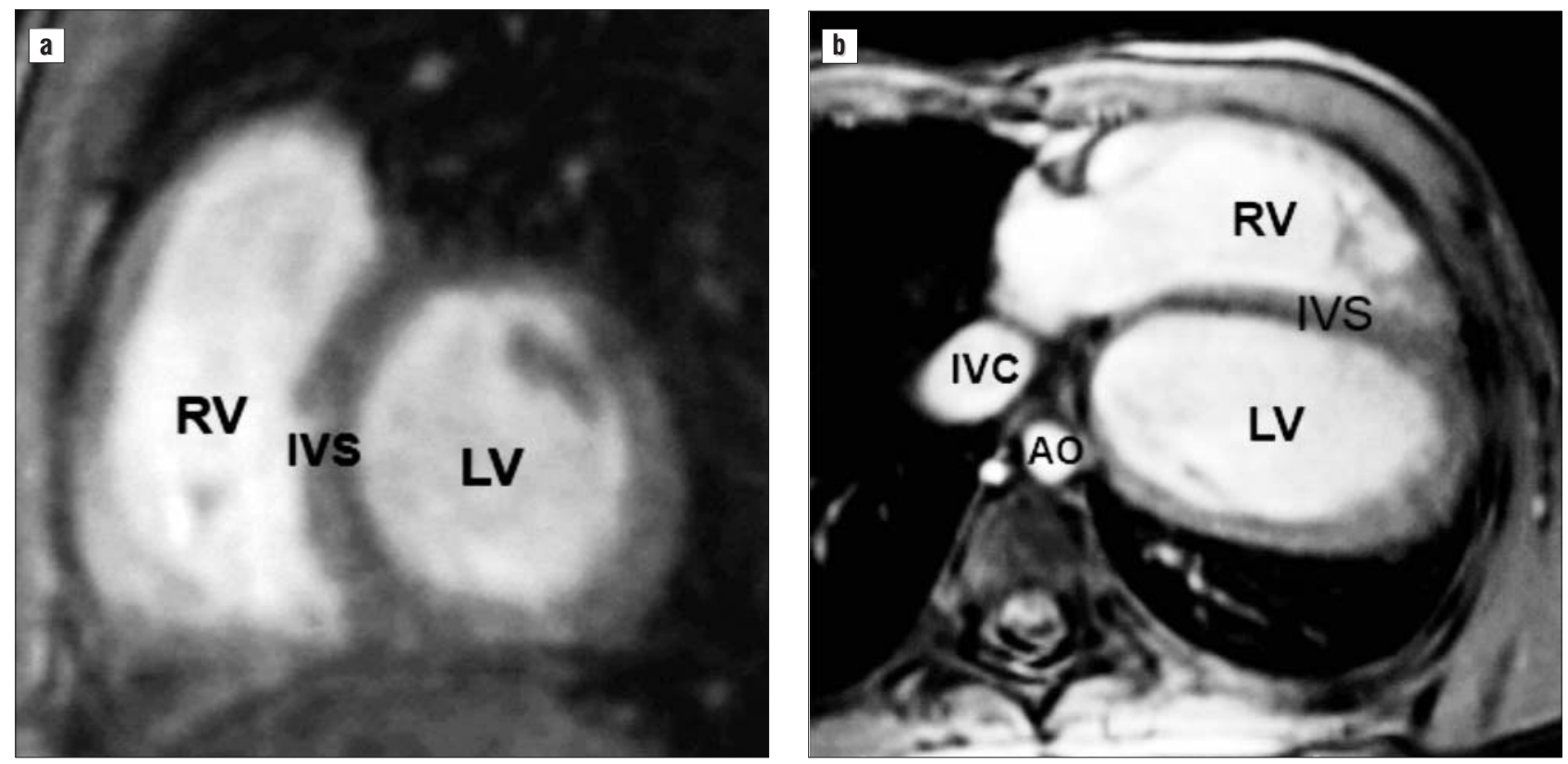

Figure 4 - CRM-CINE image in sagittal oblic short axis and axial view: no sign of left ventricular entrapment or ventricular septal defect is noted

role for the heart (3), limits the displacement of the heart in the mediastinum (8).

Usually congenital absence of the pericardium is incidentally discovered during investigations or surgical procedures made for others reasons $(3,6)$, because most patients are asymptomatic $(3,4)$. Focal pericardial defects may cause heart and lung herniation through the pericardial defect $(3,8,10)$ and ventricular entrapment (6), a serious life threatening condition $(1,2)$. In some cases with pericardial defects, chest pain $(3,11)$ and myocardial infarction were also noted, consecutive to coronary obstruction $(2,8)$.

Chest $X$ ray shows rotation of the heart to the left side $(3,12)$, without tracheal deviation $(4,12)$, an illdefined right cardiac border (13), prominent left cardiac border (3) and interposition of the lung between the left diaphragm and the inferior cardiac border (12).

Echocardiography shows left displacement of the heart (4), cardiac hypermobility and teardrop appearance (4), falsely enlarged right ventricle (14).

Cardiac-CT demonstrates extension of the pericardial defect (1), cardiac levorotation (14), interposition of the lung through the pericardial defect"retroaortic air" sign (1), also may reveal complications associated with this anomaly: ventricular herniation, left appendage strangulation etc (16).

CMR represent the best imaging tool for delineation and extension of the pericardial defects $(3,15)$.

CMR imaging shows also indirect signs of pericardial defects $(6,7)$ : abnormal position of cardiac struc- tures with important leftward displacement $(7,8)$, interposition of the lung between the diaphragm and inferior cardiac border or between the aorta and arterial pulmonary trunk (7)-the most specific sign (14). In addition to this, CMR imaging may demonstrate other cardiac abnormalities, including possible focal myocardial infarctions $(2,6)$. CMR imaging can diagnose cardiac herniation due to a partial pericardial defect (6).

\section{Imaging recommendations:}

- CMR ECG synchronized acquisition: black-blood T1 weighted spin-echo and Cine-MR imaging for the morphologic study $(3,8)$, small field of view improves pericardial visualization (8); Cine steady-state free precession (SSFP) - MR imaging for functional analyses (8)

\section{What does the clinician want to Know?}

- Type of pericardial defect (partial, complete, left or right side),

- Extension of the pericardial defect,

- Signs of complication: herniation or incarceration of the cardiac chambers, myocardial necrosis.

\section{Complications, course and prognosis}

Complete pericardial absence is considered benign and no treatment is indicated (18). Partial pericardial absence, especially foramen-type subgroup, may lead to heart and lung herniation through the pericardial defect (17), herniation of the left atrial appendage with 
consecutive infarction (8), coronal artery compression with myocardial necrosis $(2,8)$, traumatic aortic dissection secondary to cardiac hypermobility (17).

Surgical pericardioplasty is required in case of large cardiac herniation or incarceration (17).

\section{CONCLUSIONS}

Congenital pericardial defects represents a challenging diagnosis. CMR represent the best imaging tool to delineate the pericardial defect and others associated congenital abnormalities. For an early diagnostic, the radiologists should be accurate in recognizing the characteristic imaging findings suggestive for a complete absence of the pericardium.

\section{REFERENCES}

1. Koo CW, Newburg A. Congenital absence of the right pericardium: embryology and imaging. J Clin Imaging Sci. 2015 Feb 27;5:12. doi: 10.4103/2156-7514.152338. eCollection 2015.

2. Brulotte S, Roy L, Larose E. Congenital absence of the pericardium presenting as acute myocardial necrosis.Can J Cardiol. 2007 Sep; 23(11):909-12.

3. Cuccuini M, Lisi F, Consoli A, Mancini S, Bellino V, Galanti G, et al Congenital defects of pericardium: case reports and review of literature. Ital J Anat Embryol. 2013;118(1):136-50.

4. Tariq S, Mahmood S, Madeira S, Tarasov E. Congenital complete absence of pericardium masquerading as pulmonary embolism. Heart Views. 2013 Jan;14(1):29-32. doi: 10.4103/1995-705X.107118.

5. Zhen J. Wang, Gautham P. Reddy, Michael B. Gotway, Benjamin M. Yeh, Steven W. Hetts, and Charles B. Higgins. CT and MR imaging of pericardial disease. Radio Graphics. 2003;23:S167-S180.

6. Bueno Palomino A, Palomar Estrada A, Crespín Crespín M, García Fuertes D. Congenital complete absence of pericardium in a young woman with non-specific symptoms. Rev Port Cardiol. 2014 Apr; 33(4):249.e1-5. doi: 10.1016/j.repc.2013.10.015. Epub 2014 May 13.

7. Psychidis-Papakyritsis P, de Roos A, Kroft L. Functional MRI of congenital absence of the pericardium. American Journal of Roentgenology. 2007;189: W312-W314. 10.2214/AJR.05.1655

8. Bogaert J, Francone M. Pericardial disease: value of CT and MR imaging. Radiology. 2013 May;267(2):340-56. doi: 10.1148/radiol. 13121059.

9. Ono S, Ichikawa T, lino M, Yamada Y, Sekiguchi T, Nakagawa T, et al Congenital pericardial defect: a case of right pericardial partial absence with normal partial pleura. Jpn J Radiol. 2015 Mar;33(3):153-6. doi: 10.1007/s11604-014-0387-9. Epub 2015 Jan 9.

10. Kamata T, Yoshida S, Iwata T, Nakatani Y, Yoshino I. Giant bronchogenic cyst with pericardial defect: a case report\&literature review in Japan. J Thorac Dis. 2016 Aug;8(8):E684-8. doi: 10.21037 /jtd.2016.06.65

11. Arezou Zoroufian, Shapour Shirani, Behareh Eslami, Mohammad Sahebjam. Congenital total absence of the pericardium: A case report. Central European Journal of Medicine. 2010; 5(3): 315-317

12. Faridah $Y$, Julsrud PR. Congenital absence of pericardium revisited. Int J Cardiovasc Imaging. 2002 Feb;18(1):67-73.

13. Garnier F, Eicher JC, Philip JL, Lalande A, Bieber H, Voute MF, et al Congenital complete absence of the left pericardium: a rare cause of chest pain or pseudo-right heart overload. Clin Cardiol. 2010 Feb; 33(2):E52-7. doi: 10.1002/clc.20607.

14. Yared K, Baggish AL, Picard MH, Hoffmann U, Hung J. Mutimodality imaging of pericardial disease. JACC Cardiovasc Imaging. 2010 Jun;3(6):650-60. doi: 10.1016/j.jcmg.2010.04.009.

15. Ilhan E, Dayi SÜ, Güvenç TS, Altay S, Dursun M, Hatipsoylu E, et al Congenital absence of the pericardium: a rare cause of right ventricular dilatation and levoposition of the heart. Cardiol J. 2012; 19(4):408-11.

16. Abbas AE, Appleton CP, Liu PT, Sweeney JP. Congenital absence of the pericardium: a case report and review of literature. Int J Cardiol. 2005 Jan;98(1):21-5.

17. Rajiah P. Cardiac MRI: Part 2, Pericardial diseases. AJR Am J Roentgenol. 2011 Oct;197(4):W621-34. doi: 10.2214/AJR.10.7265.

18. Shah AB, Kronzon I. Congenital defects of the pericardium: a review. Eur Heart J Cardiovasc Imaging. 2015 Aug;16(8):821-7. doi: 10.1093 /ehjci/jev119. Epub 2015 May 23. 